\title{
Analysis of Critical Issues and Maintenance Activities of the Painting Process in an Agricultural and Earthmoving Machine Production Plant
}

\author{
Stefano Farné \\ Department of Electrical, Computer and Biomedical Engineering, University of Pavia, Italy.
}

DOI: http://doi.org/10.46382/MJBAS.2020.4406

Copyright: @2020 Stefano Farné. This is an open access article distributed under the terms of the Creative Commons Attribution License, which permits unrestricted use, distribution, and reproduction in any medium, provided the original author and source are credited.

Every company, in today's context of market hyper-competitiveness, must reorganize its activities due to the increased complexity of products and processes. In this perspective, expectations regarding maintenance have also changed: we have moved from the concept of production support activities to a plant management policy capable of containing the increase in maintenance costs and avoiding premature degradation of the plants. It is of fundamental importance to identify the anomalies of the processes and push the concept of Maintenance to all the activities that involve production. This article is intended to present a study conducted on the primary role of the maintenance activities and of the related critical issues, effectively conducted on the painting process in an agricultural and earthmoving machinery production plant, whose name is omitted for confidentiality reasons.

Keywords: TPM, Total productive maintenance, Agricultural and earthmoving machines, Painting process.

\section{Introduction}

\section{Maintenance functions}

Maintenance is the discipline that deals with the study, both from a design point of view and from a management point of view, of the techniques and operational actions to ensure the full availability of the systems, guaranteeing their safety and economy. This important target is pursued through complex technical and administrative actions aimed at ensuring the continuity of operation of the systems. To get an overall picture of the various maintenance aspects and the diversification of approach to problems, it is appropriate to distinguish between maintenance policy and strategy. The maintenance policy indicates the attitude of the entire organization towards maintenance problems. It is paradigmatic the case of TPM (Total Productive Maintenance), developed in Japan [1]. Sometimes this type of policy gets confused with Proactive Maintenance [2] which is only one aspect of the TPM. The innovative aspects are, mainly, the implementation of failure maintenance theories, reliability and maintainability and the introduction of a maintenance system that affects the activities of all operators. Another important example of maintenance policy is RCM (Reliability Centered Maintenance) [3], [4], which aimed at consolidating the intrinsic reliability of the project and included a number of significant phases (staff training, collection of information, division of the system, periodicity of checks, cost efficiency) which then led to the affirmation of preventive maintenance. The maintenance activity develops in three directions by acting through three different types of interventions:

1) Interventions after the fault has occurred (unscheduled maintenance);

2) Interventions according to a predetermined plan (scheduled maintenance); 
3) Continuous improvement interventions (improvement maintenance), starting from operating procedures up to the progressive redefinition of critical situations.

\section{Of fundamental importance are the different variants of preventive maintenance:}

- Scheduled maintenance, based on the analysis of reliability data (MTTR, MTBF, failure rate);

- Maintenance on condition, based on the knowledge of the actual system conditions;

- Predictive maintenance, based on the ability to predict deterioration over time through the analysis of significant parameters ("weak signals").

\section{Types of maintenance}

The primary goal of maintenance is to achieve a certain continuity of the production process. In the past, attempts were made to aim for this purpose through operational redundancies or by guaranteeing excess production capacity or simply by applying a program of revision, intervention and replacement of critical systems. All these approaches proved to be redundant and ultimately partially inefficient because the excess capacities immobilize a part of the capital that could be exploited for the production activity, just as an excessively prudent replacement program can be too expensive. So, the concept of "maintenance" evolved from considering it a repair activity to a system integrated with the production, dedicated and oriented towards prevention rather than resolution of the fault.

The maintenance activity (understood from a more strictly operational point of view) develops in three different directions:

1) occasional (or unscheduled) maintenance: also called breakdown maintenance, indicates the set of operations carried out on a device and aimed at restoring normal operating conditions following the occurrence of a fault. Failure maintenance certainly represents the oldest and simplest way to intervene and is based on the promptness of the organizational response, on the availability and skills of the maintenance technicians. This type of approach must be used in the case of sudden or catastrophic failure, that is, only in the event that a "good" maintenance activity has not given the desired results. It is therefore a question of identifying the faulty component and restoring the operational integrity of the system. The defects of this type of activity can be summarized briefly: machine stops are random; a serious failure on a single component can cause breakdowns also on other elements of the system with a strong increase in costs; unscheduled repairs involve a long time (to obtain spare parts, assign the right technician, etc.) blocking the production.

2) Scheduled maintenance: maintenance interventions arise from a logical and predetermined programmatic plan. Maintenance activities are planned by different criteria in relation to the type:

- Ordinary: it is carried out at pre-established time intervals and aims to permanently guarantee the availability of a system; - Preventive: applicable only to devices whose average (expected) life can be determined with a good margin of accuracy; this approach is aimed at anticipating the failure of a generic component and it has undoubtedly favored the cultural growth of the maintenance function. It is certainly a more valid type of 
maintenance than the previous one but involves higher costs in terms of the use of both human resources and technical materials, without however affecting the availability of the systems. The preventive maintenance, based on inspection and revision, acts on the system when it is still working but its performance is deteriorated up to the state of imminent failure. Operational activities can be divided into three classes:

a) Normal maintenance of properly operating subsystems and mechanisms that require some care by lubricating, cleaning, adjusting, changing, etc;

b) Search for redundant faulty components and any repair or replacement;

c) Overhaul or replacement of worn components.

This type of activity is based on the philosophy of failure avoidance and is carried out according to two possible ways:

- on a constant date (on condition): the principle of "if it works, don't touch it" is followed; in this way, it is not necessary to block much money to guarantee the spare parts needed to cover all eventualities (accepting however the possibility of random failures between two successive interventions);

- on a constant period (according to a schedule): maintenance is carried out at constant intervals (time based maintenance), at fixed calendar dates (hard time maintenance) or on the basis of parameters of machinery use (relative hours of operation, reset following the maintenance intervention).

In the event that a component is replaced following the preventive maintenance program, it is eliminated from the random failure zone of the Bath-Tub Curve, where the failure rate is minimal, and reported in the "child failure" region, i.e. where the failure rate reaches its maximum. Therefore we can conclude that following the Bath-Tub Curve model to determine the maintenance program of a mechanical system involves an increase in the overall probability of failure by lowering the reliability and conflicts with the objective of increasing the average time between two successive stops of the plant;

- Predictive (or on condition): characterized by non-destructive techniques to test systems with the aim of identifying, in advance, the presence of faults, so as to be able to organize a revision only when the conditions of the machine make it necessary. This approach has many advantages: first of all, it is a maintenance on condition that plans interventions based on the real conditions of the machine, allowing to avoid unexpected downtime or catastrophic chain reactions by improving the reliability of the entire system. This type of maintenance starts from the assumption that only rarely does a component fail in a clear and sudden way; in the majority of cases the failure occurs after a progressive deterioration. It is supported by the activities of condition monitoring and system diagnostics (series of measurements, visual inspections, non-destructive tests, operational or functional tests); these actions, at regular intervals, allow to detect the performance of a component and to evaluate its degradation. The techniques on which this methodology is based are:

- Visual monitoring: looking for fatigue cracks, welding defects, etc.; 
- monitoring of compliance with specifications: check that pressure, flow, temperature, speed assume values close to those of the project;

- monitoring of vibrations and noise;

- monitoring of wear debris.

The distinction from the previous methodology is: analyzing the trend of the monitored functional parameters, it allows forecasts based on the actual state of health of the system rather than on the elapsed operating time.

- Proactive (or productive): strategy that tends to anticipate, in conceptual and functional terms, the failure oriented approaches. If predictive maintenance underlies the early identification of faults, the proactive path embraces a set of operations aimed at eliminating or at least correcting the conditions that lead to a weakening of the system's functionality, fighting the root causes of failure and restoring the stability system. Predictive maintenance is based on the principle of providing an alert signal to the maintenance technician in advance such as to allow the scheduling of the necessary repair activities, minimizing downtime. This depends solely on the monitoring program and the need for deeper analysis in the presence of inaccurate data. In proactive maintenance, on the other hand, an attempt is made to carry out, in advance of any damage to the material or to the performance of the system, a pre-alert activity. That is, a series of actions aimed at correcting the conditions that can lead to the deterioration of the system. Proactive maintenance aims at identifying and correcting abnormal values of the root causes of failure that would lead to operational instability. The latter are the "roots of the failure" and signal the first level of malfunction called conditional failure. This kind of maintenance is the first tool of defense against the degradation of the material (incipient failure) and the consequent weakening of the performance (imminent failure) which lead to the inevitable breakdown. This guarantees high levels of use of the components and a very high reliability value with a large impact on the values of the failure rate and of MTBF. In the initial phase, the maintenance technician is called upon to carry out a monitoring activity of the key parameters, evaluating the criticality of the root causes of failure: if instability is found, it means that there is a conditional failure; after this first phase, a correction of the identified critical factors follows. The techniques on which this methodology is based are:

- monitoring of key parameters indicative of the state of the system (level of contamination of the lubricating fluid);

- definition of the acceptable threshold values for each parameter;

- recognition and analysis of anomalous values that indicate instability of operating conditions;

- specification of the corrective methods to be applied to resolve the root causes of failure and restore system stability.

\section{Specific improvement, productive maintenance}

The TPM is based on five basic activities [1], the first of which is to increase the efficiency of every single part of a plant that suffers damage. Engineers, maintainers, line supervisors and team members are organized into project groups that try to eliminate any problems that slow down production. In the first period of application of the TPM 
there will always be someone who doubts that this approach can really lead to positive results despite it has been shown that this system, in other companies, has increased the productivity level and the quality of the products obtained with a strong reduction in costs, with a consequent improvement in economic results. In each department it is necessary to select the machines that have chronic failure conditions and assign each machine to a team. Team managers can certainly take advantage of the experience gained in improving other plants in the various production centers. The TPM analysis is an effective tool for analyzing chronic conditions and it consists of:

- define the problem. The problem should be examined carefully and the symptoms and parties involved should be compared with other cases that have already occurred;

- make a physical analysis of the problem, to clarify consequences and damages;

- isolate the conditions causing the problem. It's needed to check the physical principles that cause the onset of problems and explore every possible cause;

- evaluate plants, materials and methods. Every constraint of the plant, equipment, materials and operating methods must be considered by drawing up a list of the factors that influence the operating conditions;

- develop inspection techniques. It is necessary to choose the measurement techniques of the significant quantities, identify the appropriate criteria and establish the objectives of the inspections;

- remove disturbing elements;

- make suggestions.

The second of the five activities, self-maintenance, is one of the key steps in the development program. The distinctive feature of the TPM is precisely the autonomous maintenance performed by individual operators. According to the previous organizational schemes, the production workers are used to occupy all the time of the working day in the production activity, and the maintenance staff takes on all the related tasks.

Therefore, habits and old rhythms cannot change quickly but changing the way of thinking within a factory requires a certain period of time. In the initial phase, all production workers must be convinced that they can organize maintenance themselves and become personally responsible for the machines. In addition, production workers must be updated and trained to improve and enhance skills so as to enable them to take care of maintenance independently.

The five "S": seiri, seiton, seiso, seiketsu and shitsuke (organization, order, purity, cleanliness and discipline) are the basic principles of management. It is necessary to refrain from superficial autonomous maintenance interventions, worrying only about appearances and the seven-point system must be adopted, making progressive improvements in each of the 5 "S". We summarize the seven-point method developed by Gotoh Fumio [5]:

1) Initial cleaning. By cleaning the machines entrusted to them, workers develop a better knowledge and a deep attachment to the machine. The operators learn that cleaning, checking the lubrication and screwing of the bolts is equivalent to daily testing.

2) Countermeasures for causes and effects of dirt and dust. Countermeasures must be taken to eliminate dust, dirt, leaking coolants and lubricants. 
3) Standard of lubrication and cleaning. In points 1 and 2 the workers identify the characteristics of the plants entrusted to them. The standards of speed, efficiency and optimal maintenance are then established to prevent deterioration. The time available for cleaning, lubricating and screwing is obviously limited. The supervisors allot the workers a reasonable time for all these operations (for example 10 minutes for each shift change, 30 minutes at the end of the week, one hour per month). If standard operations cannot be performed within their allotted times, cleaning or lubrication procedures need to be improved. These improvements can be achieved by introducing new methodologies and new inspection techniques, such as visual checks of level gauges in lubrication equipment, etc. In this case the workers can make the changes with the cooperation of the supervisors.

4) General inspection. Points 1 to 3 try to pursue the prevention of deterioration of the machines and the control of the basic operating status. At this point, however, we take care of measuring the state of deterioration of the systems with a general inspection. At the beginning, the TPM group leaders are helped by manuals specially prepared by the supervisors to spread, to all interested operators, what they have learned from the first interventions. The team members work collaborating to solve the problems that emerged during the total inspection and with the assistance of the maintenance function they restore the conditions of the affected area. There are some logical steps to follow when training and organizing personnel for inspections. The inspection training must be done category by category and its effectiveness must be verified with field tests and additional preparation courses. It is certainly a longer phase than the others as all operators must have the time to develop the skills necessary for the proper performance of these additive tasks. But at the end of this phase, the company will already notice satisfactory results such as an $80 \%$ reduction in plant failures.

5) Autonomous inspections. In the previous points, operators were trained in general inspection operations, while the maintenance department prepared an annual maintenance program. Therefore it will always be necessary to compare the standards assumed in the individual departments with those scheduled by maintenance in order to have a correspondence and correct any inaccuracies or insert missing activities or eliminate overlapping activities between departments.

6) Organization and order. Seiri means organizing and in this phase the peculiar aspects of the workplace must be identified and rules set. Seiton, means respecting established standards. The first refers to managers who must always minimize the aspects to be controlled, the second refers to operators who must comply with the standards. At this stage, therefore, simplification, organization and compliance with established standards are ensured. In this phase the role of the worker expands, he is not only the executor of the first five inspection and control phases, but through a careful evaluation of the operators by the managers, the control of the realization of the autonomous maintenance is realized and therefore the expansion of the tasks that the workers perform on the plants.

7) Complete implementation of autonomous maintenance. At the end of the process, workers feel confident, experienced and independent, able to monitor their work and make the necessary changes. At this point, all activities should lead to the elimination of the six fundamental causes of loss of production and the implementation of improvements. The fifth of the fundamental points of the TPM is the definition of a periodic maintenance program compiled ad hoc for the maintenance service. The development of a scheduled maintenance program 
must begin before the general inspection procedures (phase 4) are fully defined. Scheduled maintenance must be performed by the maintenance department itself and must be coordinated with the autonomous maintenance activities carried out by the departments. To achieve a complete and effective inspection, the division between the responsibilities of the two departments must be clear. The starting point in the management of planned activities is always the analysis of failure modes. For each detected fault, the presence of a weak signal is sought to identify the imminent appearance of breaks (for example, the evaluation of the change of some parameters). If it is possible to identify the presence of a weak signal, then one must also question the monitoring methods of the same. If the signal can be monitored, in addition to the recalibration of the control intervals, predictive maintenance will be carried out. On the contrary, if the signal cannot be monitored, an attempt will be made to evaluate the forecast of the component that suffers the failure. In the event that the expected duration is known but inspection of the component is not possible, the only maintenance policy is that of scheduled maintenance. If the failure mode has no signals and has no forecasts of duration, the only activity that can be performed is emergency maintenance. If scheduled maintenance is inadequate in a company, the maintenance department must re-evaluate the inspection activities of each individual part of the machine, molds, equipment, technical documentation, etc. Production line maintenance is regularly performed during scheduled production stops in the working week. A key feature of this typology is the maintenance meeting held daily in which all the production line managers, maintenance shift managers and technical office staff participate in deciding line stops and maintenance work. This favors a quick definition of the weekly and monthly calendar of maintenance interventions and a correct management of breakdowns and daily stops.

\section{Materials and methods}

\section{The agricultural and earth moving machinery production plant}

The production of the examined plant focuses on tractors, wheel loaders, telehandlers and crawler dozers. The dimensions and the plant layout are indicated in what follows.

\section{Total area}

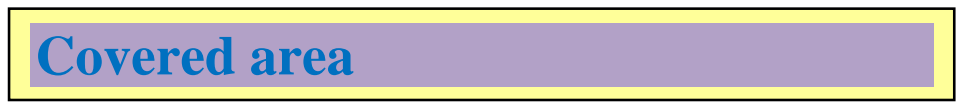

\section{Workshop}

Offices \& Services

Testing centre / Laboratory

\section{Training centre}

$592.000 \mathrm{sqm}$

$153.000 \mathrm{sqm}$

$134.000 \mathrm{sqm}$

$12.000 \mathrm{sqm}$

$8.000 \mathrm{sqm}$ 


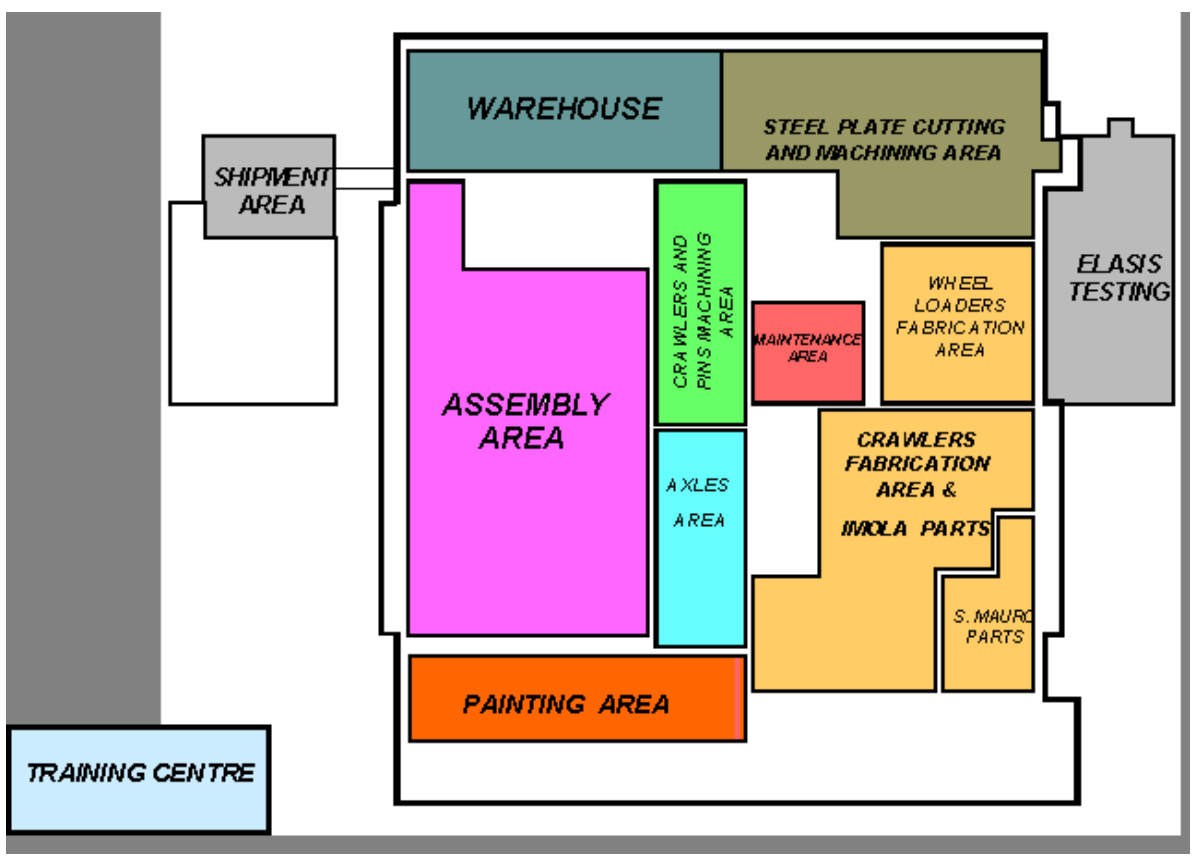

Fig.1. Plant overview and layout

$N^{\circ} 43$ MACHINING CENTRES

$N^{\circ} 12$ WELDING ROBOTS

$N^{\circ} 2$ PAINTING ROBOT SYSTEM

$N^{\circ} 6 \quad$ N/C OXICUT MACHINES

$N^{\circ} 2$ SANDBLASTING MACHINES

$N^{\circ} 2$ PAINT SYSTEMS

$N^{\circ} 1$ WHEEL LOADERS ASS'Y LINE

$N^{\circ} 2$ CRAWLERS ASS'Y LINES

$N^{\circ} 1$ TELEHANDLERS ASS'Y LINE

$\mathrm{N}^{\circ} 1$ DIMENSIONAL CHECK SYSTEM

\section{Description of the painting plant}

\section{Technical features}

\section{1) WORKING CAPACITY}

Agricultural and earthmoving machinery components

Material: steel

\section{2) PRODUCTION DATA}

Product: groups / components of machines 
Material: steel

Front section of the group/component (width x height): 1.6 x $1.8 \mathrm{mt}$.

group/component length: $3.7 \mathrm{~m} \max$

Load on hanger: $2000 \mathrm{Kg}$. Max

( $2500 \mathrm{Kg}$ for the dimensioning of the support structure)

Maximum treatable surface: 100 sq.m./h approx.

Conveyor speed: $0.35 \mathrm{~m} / \mathrm{min}$. ca.

conveyor type: Two-rail overhead Morris 6 "

3) PAINTING CABIN FOR ENAMEL APPLICATION

Cabin technical data:

Length $8 \mathrm{~m}$

Width $6 \mathrm{~m}$

Internal height $4.8 \mathrm{~m}$

- washing water: $240 \mathrm{mc} / \mathrm{h}$

- air speed: $0.5 \mathrm{~m} / \mathrm{sec}$. $+/-0.1 \mathrm{~m} / \mathrm{sec}$.

- input air: $87000 \mathrm{mc} / \mathrm{h}$

- extracted air: $87000 \mathrm{mc} / \mathrm{h}$

Illumination: 600 Lux at 1m. from the ground calculated at the half life of the lamps (series of fluorescent lamps, external to the cabin)

4) ENAMEL DRYING TUNNEL

Technical data of drying tunnel:

Length $12 \mathrm{~m}$

Width m. 4.8

Internal height m. 6.5

- Time spent in the tunnel: $10 \mathrm{~min}$

- -Operating temperature: ambient

- $\quad$-Air introduced: $10000 \mathrm{mc} / \mathrm{h}$

- $\quad$-Air extracted: $10000 \mathrm{mc} / \mathrm{h}$

5) ENAMEL DRYING OVEN

Technical data drying oven: 
Length m. 28.5

Width m. 4.45

Height m. 6.5

- $\quad$-Time spent in the oven: $60 \mathrm{~min}$

- -Operating temperature: $110^{\circ} \mathrm{C}$

- $\quad$-Air in recirculation: $660000 \mathrm{mc} / \mathrm{h}$

- $\quad$-Air extracted: $4000 \mathrm{mc} / \mathrm{h}$

- $\quad$-Potentiality: $480000 \mathrm{Kcal} / \mathrm{h}$

6) ENERGY SOURCES REQUIRED BY THE PLANT

ELECTRICITY: power voltage (400 V three-phase), lighting voltage (230 V single-phase, frequency $(50 \mathrm{~Hz})$, control circuit voltage (110 V single-phase)

COMPRESSED AIR: nominal pressure (6 bar at uses-dehydrated and de-oiled)

METHANE GAS: nominal pressure for oven burners $(200 \mathrm{~mm})$, for burner in air flow for central air handling unit $(1500 \mathrm{~mm})$, minimum calorific value $(8500 \mathrm{kcal} / \mathrm{Nmc})$

INDUSTRIAL WATER: nominal pressure (3 bar)

INSTALLED THERMAL POWER: for the enamel application booth

$(600000 \mathrm{kcal} / \mathrm{h})$, for the glaze oven $(480000 \mathrm{kcal} / \mathrm{h})$

INSTALLED MECHANICAL POWER: $180 \mathrm{~kW}$ approx.

INDUSTRIAL WATER CONSUMPTION: $1000 \mathrm{lt} / \mathrm{h}$ approx.

Analysis of the critical issues and maintenance activities in the painting department

\section{Painting cycle}

In the painting department of welded groups (components / agricultural machinery groups) of the plant, anomalies of different types were found. It was therefore necessary to analyze the criticalities of the process to try to optimize it and to eliminate the causes of the defects found on the pieces. To try to pursue this goal, it is necessary to know the system and the entire cycle of the painting process in order to identify and to analyze all types of defects that must be sorted by frequency to focus attention on the most frequent ones.

After identifying the defects to be analyzed, it is necessary to correlate the effect (the defect on the piece) to the causes, investigating more and more specifically to understand all the related operations. It is therefore necessary to monitor the system, recording and detecting defects on the parts to be repaired and involving the operators in the improvement activity, in order to identify all possible causes. Based on the data collected, on the observations/ suggestions of the employees and on the analysis of the process, it is necessary to define and implement the 


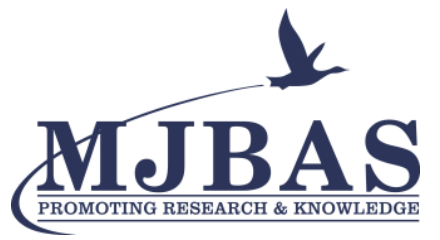

Mediterranean Journal of Basic and Applied Sciences (MJBAS)

Volume 4, Issue 4, Pages 136-166, October-December 2020

appropriate corrective actions. In the following list they are summarized what the objectives of the painting department are and what the customer actually expects regarding the painting:

- Aesthetics

- Brilliance

- Fullness

- Uniformity

- Shine

- Resistance

- Conservation of color and brilliance

- Resistance to corrosion and blistering

To obtain these characteristics, the groups / components are treated by:

1. Corrosion protection:

- Pre-coated sheets.

- Anti-corrosion primer application.

2. Embellishment:

- $\quad$-Spray colored nail polish - bright.

\section{1- LOADING ON CONVEYOR}

\section{3- CHECK AND CLEANING}

2- PRE-TREATMENT (BLASTING)

\section{4- CHECK AND CLEANING}

\section{5- BOTTOM DRYING}

\section{7- ENAMEL PAINT}

\section{8- ENAMEL DRYING}

Fig.2. Process Scheme 
Figure 2 illustrates the process scheme. The welded components / assemblies must be hung from the transport system with care and with particular attention, to facilitate painting and to avoid collisions with the walls of the painting cabin, with the painting robots, with the walls of the oven.

1) PRE-TREATMENT (BLASTING)

Purpose: to clean the surface of the welded components from any traces of oxidation to help anchor the paint film.

2) CHECK AND CLEANING

Purpose: Check the correct execution of the above and vacuum up any shot blasting.

3) FUND APPLICATION

Purpose:

- Give the final layer of paint good mechanical resistance.

- Increase protection by isolating the underlying layers from solar radiation.

- Create the best support / adhesion conditions for subsequent top coats.

The operation takes place in a cabin (see figure 3 and 4), where a base paint of a neutral color (or of some shades such as light gray, dark gray) is sprayed on all the surfaces of the welded groups. The primer layer has a dry thickness of $35-40 \mu \mathrm{m}$. The paint consists of polyester resin and pigments, it can be diluted with organic solvent.

\section{4) BOTTOM PAINT COOKING}

It takes place with air introduced at a temperature of $60-65^{\circ} \mathrm{C}$ for $50-60$ minutes in a continuous tunnel oven. The gradual heating of the welded groups during the advancement produces first the evaporation of the last traces of solvent, then the polymerization of the resins.

\section{5) CONTROL}

The coverage of the bottom, the presence of micro defects in the film, for example drippings, dust spots, etc. are checked by localized interventions to ensure a base surface suitable for receiving the final layer of enamel:

- $\quad$ search for defects and elimination by manual sanding with buffers and standard grain size sandpaper.

- blowing and cleaning of all areas affected by overhaul interventions.

\section{6) ENAMEL APPLICATION}

Purpose:

- $\quad$ provide the final aesthetic appearance of the component (color, brilliance and homogeneity);

- guarantee resistance over time to atmospheric and chemical agents.

The application operation takes place in a cabin:

- a spraying stage of base enamel to form a layer $130-160 \mu \mathrm{m}$ thick. This layer is achieved by using painting robots;

- polymerization of the enamel in the oven at a temperature of $80{ }^{\circ} \mathrm{C}$. 
The base enamel is the one that determines the final color of the piece and is made up of polyester resin diluted with organic solvent. The painting is done inside a cabin with air inlet from above for the abatement of dust. The over spray abatement system is of the Venturi type. This washer allows very high efficiency with particulate matter in the chimney $<3 \mathrm{mg} / \mathrm{Nmc}$. The cabin is made with a box-type structure with large surfaces side windows with air diffusion plenum positioned above the filtering ceiling, vertical descending ventilation and central extraction under the grid with pigments abatement washers. The thermoregulated air in the inlet group described below is introduced into the plenum through a filtering surface constituting the ceiling of the cabin itself, equipped with filter panels capable of achieving a uniform distribution of air along the entire length of the cabin. The excess product "mists" are then taken up by the descending air flow.
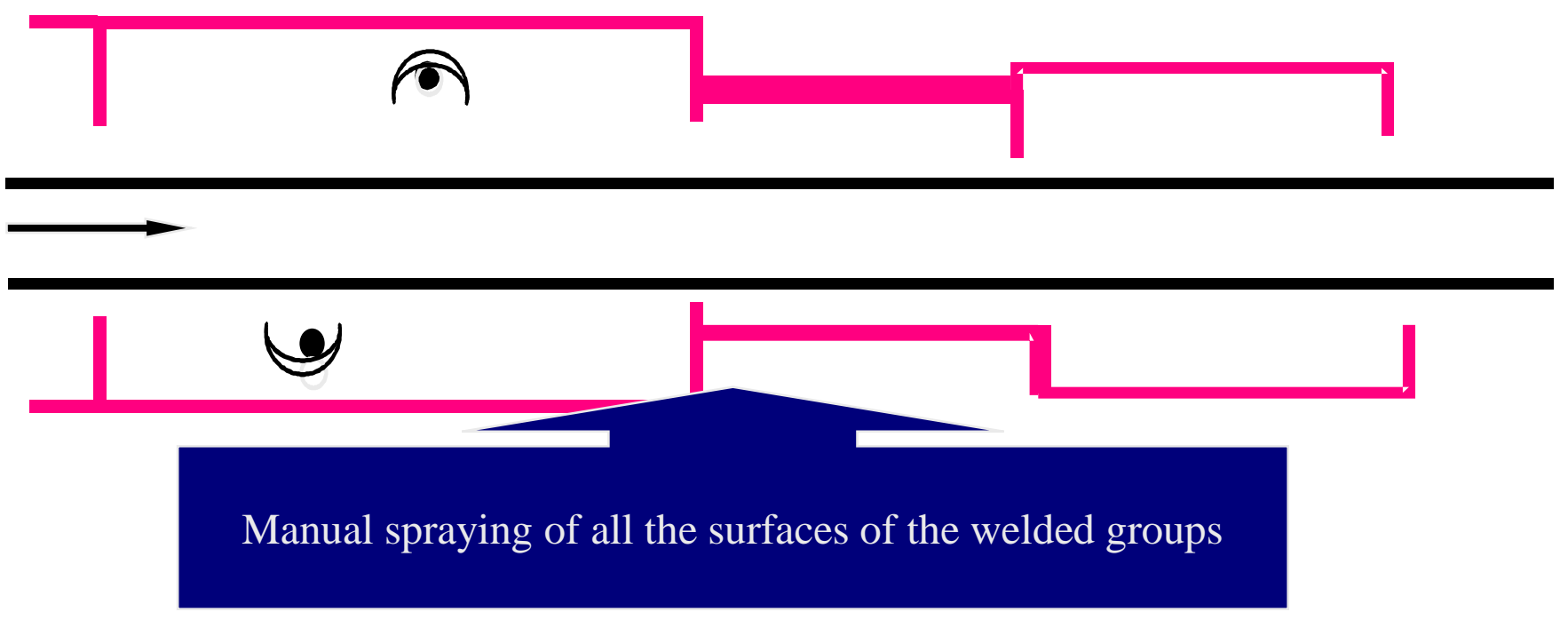

Fig.3. Painting cabin lay-out

\section{7) ENAMEL PAINT COOKING}

Before drying the enamel, the pieces pass through the tunnel withering to suck and expel the volatile parts of the paint sprayed on the pieces. The tunnel is in-line and its structure is modular consisting of uprights in metal profiles and made in such a way as to support the weight of the runways and the pieces weighing on it, the side paneling, the ceiling, and the channels air distribution. The air is taken from the air handling unit of the spray booth and fed into the tunnel. At the same time, to evacuate the fumes, the exhausted air from the drying tunnel is sucked in by the extractor of the cabin itself. The drying takes place in the drying oven after the pieces have come out of the drying tunnel. Operating temperatures of up to about $110^{\circ} \mathrm{C}$ are reached inside the oven. The conveyor inside the oven has a rectilinear layout that allows the pieces to stay for about 60 minutes. The oven consists of a main load-bearing structure, made up of connecting columns and beams designed to support the insulated walls and the transport system. All walls are made by insulated panels (180 mm thick) to limit heat dispersion. All the carpentry of the oven rests on the floor. The oven is in-line with the heat generator positioned on the floor.

\section{8) UNLOADING}

There is an area for unloading and checking the painted pieces. 


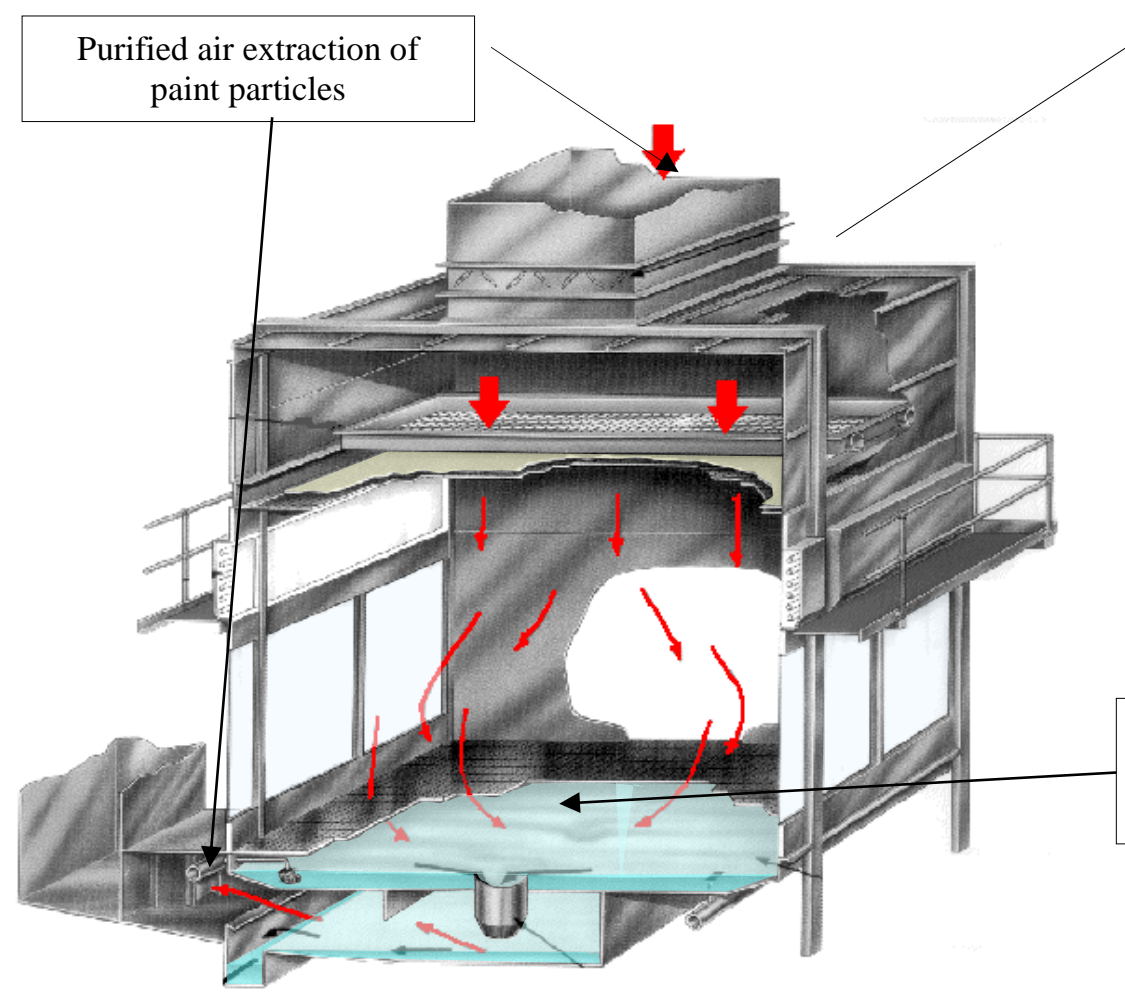

Air conditioning intake (clean and at a controlled temperature)

The application takes place by spraying the surfaces in a booth with forced air circulation where the paint over spray is dragged by the air towards the grilled floor of the booth and captured by a flow of water in a Venturi-type system. The purified air is extracted and expelled.

Water containing paint over spray sent to depuration

Fig.4. CABIN Section

\section{Data Collection and Analysis}

To analyze the situation, the data that characterize the phenomenon of interest have been collected and numerically ordered (table 1).

\begin{tabular}{|c|c|c|c|c|c|c|}
\hline & $\begin{array}{c}\text { PARTS } \\
\text { DETECTED } \\
\text { DEFECTIVE }\end{array}$ & DAY & $\begin{array}{c}\text { DISCOVERED } \\
\text { (COLATURE) } \\
\text { PARTS } \\
\text { (PARTI } \\
\text { SCOPERTE) }\end{array}$ & GRINDING & $\begin{array}{c}\text { DEFECTS OF } \\
\text { BLASTING }\end{array}$ \\
\hline & 1 & 1 & 3 & 0 & 0 & 0 \\
\hline & 3 & 2 & 3 & 1 & 1 & 0 \\
\hline & 1 & 3 & 1 & 2 & 0 & 0 \\
\hline & 2 & 4 & 2 & 1 & 0 & 1 \\
\hline & 4 & 6 & 2 & 2 & 0 & 0 \\
\hline tot. & 1 & 7 & 3 & 4 & 1 & 0 \\
\hline
\end{tabular}

Table 1 
To evaluate the most important defect on which to focus the analysis, we used an histogram diagram, that allowed us to identify and represent priorities with a graphical methodology and made it easier to take decisions. Based on the analysis carried out, we focused our attention on the two main types of defects: drippings (colature) and uncovered parts of paint (parti scoperte di vernice). A further analysis was performed to identify the critical areas of the welded groups affected by the problem of dripping and / or lack of paint (see figures 5,6,7). We carried out an examination of the parts sent for repair to identify the geometrically complicated areas and we noticed a duality of the two recurrent anomalies in the same areas: there were uncovered areas of paint and areas that were too covered with consequent drippings of the non-pulverized paint in an optimal manner.

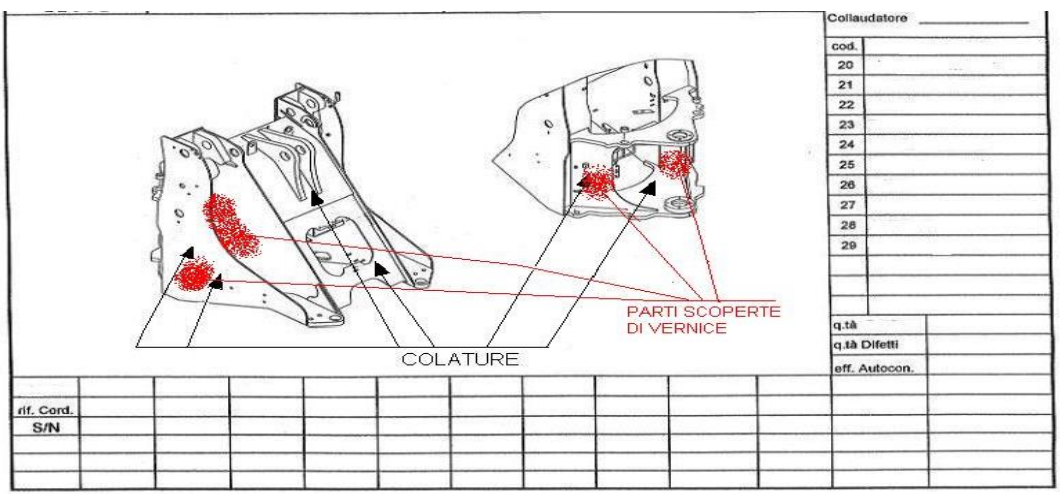

Figure 5

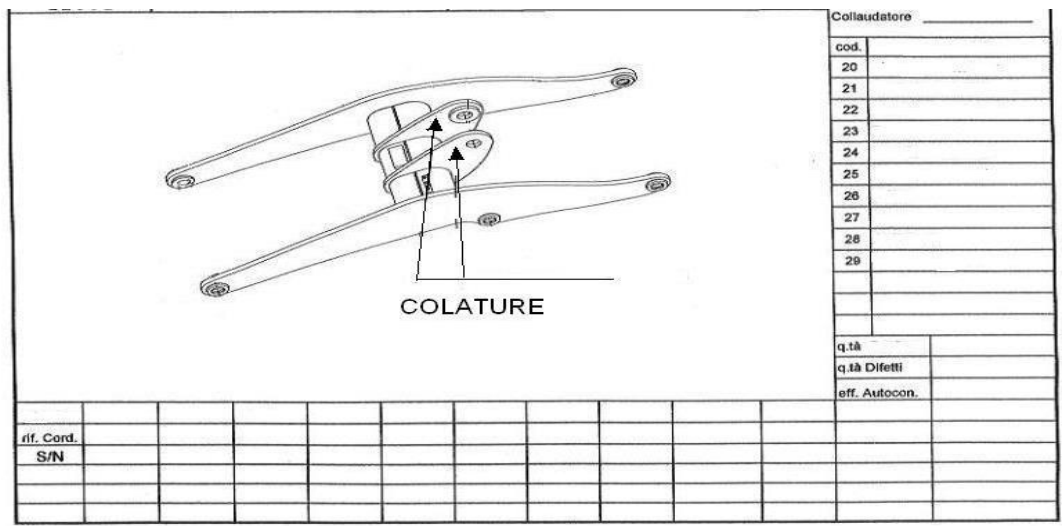

Figure 6

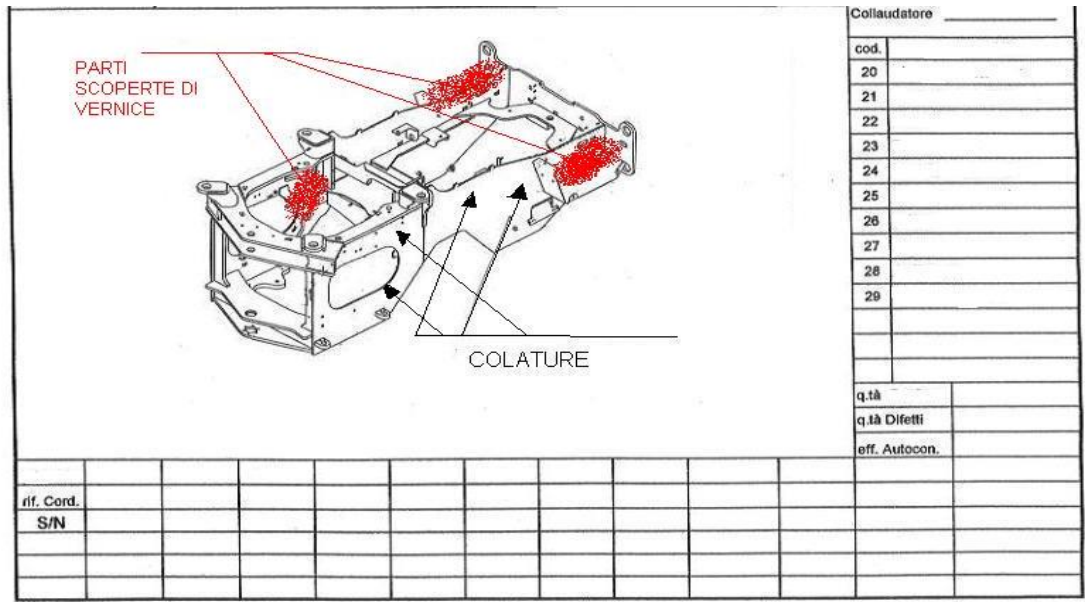

Figure 7 


\section{TPM in the painting department}

The TPM in the agricultural and earthmoving machinery factory is a system that, involving all company functions, aims at maximizing plant efficiency and optmized work organization. The project was based on the division of the organization into two main structures:

1) Project Management Structure: there is collaboration between the workers of the various teams (workshop TPM groups) and the technicians and operators (development TPM groups) to reach and implement improvement actions from the point of view of safety, quality and efficiency.

2) Operational Plan: it is divided into two macro-phases and reports all the phases to be achieved; the first phase seeks to improve production efficiency through the reorganization of the work areas according to the concepts of the $3 \mathrm{~S}$, the second seeks to improve the efficiency of the machinery through the autonomous maintenance system.

The first step of the $3 \mathrm{~S}$ includes all the behavioral and organizational activities mentioned in the $5 \mathrm{~S}$ technique (seiri, seiton, seiso, seiketsu and shitsuke: organization, order, purity, cleanliness and discipline). The second step, as can be seen from the operational plan, includes all PV / CIL activities ("Prevention-Visibility" and "Cleaning-Inspection-Lubrication"). The third step A-I-M ("Autonomous Inspection Maintenance") aims at improving the overall efficiency of the machinery by reducing the "6 Big Losses":

1) Losses for Failures

Losses due to failures are those due to the machine being stopped and the downtime is represented by the intervention and repair time by maintenance.

2) Losses for Equipment and Adjustments

Losses of this type are caused by tool and material changes and time required to set up the machine

3) Losses for Vacuum and Microstops.

These are the losses due to micro-stops to try to solve the problems of the machines in an incomplete way and not lose the rhythm of production.

4) Speed Reduction Losses.

Losses for this type of defect are due to multiple causes: loosening of the belts, lack of specifications on the production speed and lack of knowledge on the load conditions of the machinery.

5) Losses for Defects and Repairs

Losses due to defects are those due to the production of defective parts.

6) Loss of Yield on Start-up

They are a type of losses similar to adjustments after setups. 
To reduce all these losses it is necessary for the operator to record the anomalies and machine stops on a special card through a systematic analysis of the system. Only in this way it is possible to analyze the anomalies and make the right improvement actions. The fourth step includes continuous improvement which is equivalent to learn how to use the tools of the TPM. To be connected to the TPM is the self-control procedure which, within the Company Management System, specifies the general criteria, responsibilities, operating methods and tools necessary to guarantee, at each stage, the control of production processes through the involvement of all the employees. The general self-control system consists in a set of documentation that is managed from the "figure cutting" to the final delivery. Self-control refers to the following areas:

- figure cutting department

- mechanical carpentry department

- mechanics

- painting

- assembly line (subgroups / groups and completion line)

- functional testing

- final delivery

Self-control is the activity of verifying the quality of the product being manufactured, performed directly by the employees at each operational phase through the application of documented instructions, in order to ensure product compliance with the requirements or specifications. It represents the system's ability to self-regulate, effectively eliminating any causes of process failure. Self-control, currently applied and managed, produces the following benefits on the system:

- it prevents the non-compliant product of each phase from being delivered to the next phase and / or department;

- it provides information to solve repetitive cases of non-compliance;

- it allows immediate intervention on the basis of objective information;

- it provides data for process improvement activities;

- it motivates and sensitizes all production staff to quality;

- it allows a reduction in losses connected with product defects;

- it allows better management by the team leader.

To develop a complete and effective self-control system it is necessary:

- to know the flow of internal production processes and their subdivision by departments up to final delivery and shipment;

- to know the process within which the group is produced for which self-control must be defined;

- to have defined the manufacturing cycles for that group and the corresponding self-control cycles;

- to have defined the various stations that make up the process of that group;

- to know the critical parameters to be controlled, their acceptability characteristics and the control tools present in each station; 
- to have defined the documentation that must accompany the group from the first pieces (instructions, cards, certificates of conformity) to the next department and how the archiving should take place;

- to have an operational system for the management of non-conformities and corrective actions.

The means through which self-control is carried out are:

1) Personalized self-control cycle for each department and in the station to which the cycle refers, which must indicate:

- $\quad$-operating modes;

- the characteristics to be checked;

- control tools and frequencies.

2) Self-check Registration Form, specific for each component or lot, reports:

- the detailed indications of the features from check, specific for each department, of the component to which thr form refers, with relevant acceptability criteria

- the registration of the check with a result (OK; NOK) permitting,

- hence the traceability of controls. The card accompanies the

- piece up to the last phase of the department process interested; it also has a space reserved for recording of measures in case of non-compliance.

3) Self-control instruction, used only in some departments as prescribed below and recalled by the corresponding cycle of self-control.

4) To limit the quantity of registration cards in circulation, at the end of some processes, they are collected and filed, while it is issued a declaration of compliance that becomes the only document that travels between a department and the subsequent ones. It accompanies the piece and must be sent to the next stage only if the dates and signs of the previous phases are present, to ensure that all operations performed comply with the requirements contained in the cycles of self control. For those departments whose processes are considered by single self-check registration card, latter acts as a Declaration of Conformity.

Each station must be equipped with:

- Self-control cycle

- Self-check Registration Form

- Flow chart of the different operations

- Declaration of conformity

\section{Self-check in the painting department}

The painting department consists of:

- Jolly system painting

- Retouching painting, for assembled groups and complete machines 
During the painting process, it was considered essential to define specific controls relating to the following phases that affect compliance with the entire cycle:

\section{PAINT PREPARATION IN THE CENTRAL UNIT}

When a paint barrel is required from the line, the plant operator carries out the operations as specified in the "Paint Preparation" self-control cycle (figure 8). The operator marks the results on the appropriate "paint preparation registration form".

\section{CHECK PLANTS AND DEVICES}

At the beginning of the shift, the employee checks the status of the system and the paint as specified in the painting system self-control cycle (figure 9) and records the result on the Jolly painting self-control registration card. If the system is not compliant, the team leader requires the repair of the system and decides independently, or in consultation with his leaders, whether or not to continue the production.

\begin{tabular}{|c|c|c|c|c|}
\hline & \multicolumn{3}{|c|}{$\begin{array}{l}\text { SELF-CHECK CYCLE } \\
\text { PAINT PREPARATION }\end{array}$} & $\begin{array}{l}\text { Issued on } \\
\text { Revision nr }\end{array}$ \\
\hline \multicolumn{2}{|l|}{ ALL MODELS } & \multicolumn{3}{|c|}{ APPLICABILITY: ALL COLORS } \\
\hline CHARACTERISTIC & CONTROL & I. FREQUENCY & $\mathbf{R}$ & NOTES \\
\hline $\begin{array}{c}\text { CHECK PAINT COLOR AND } \\
\text { TEST NR. }\end{array}$ & VISUAL & Every shift start & $\mathbf{X}$ & \\
\hline TO CHECK PAINT CODE & VISUAL & Every shift start & $\mathbf{X}$ & \\
\hline $\begin{array}{c}\text { ROTATE YHE PAINT DRUM } \\
\text { FOR AT LEAST } 10 \text { minutes }\end{array}$ & & Every shift start & & \\
\hline
\end{tabular}




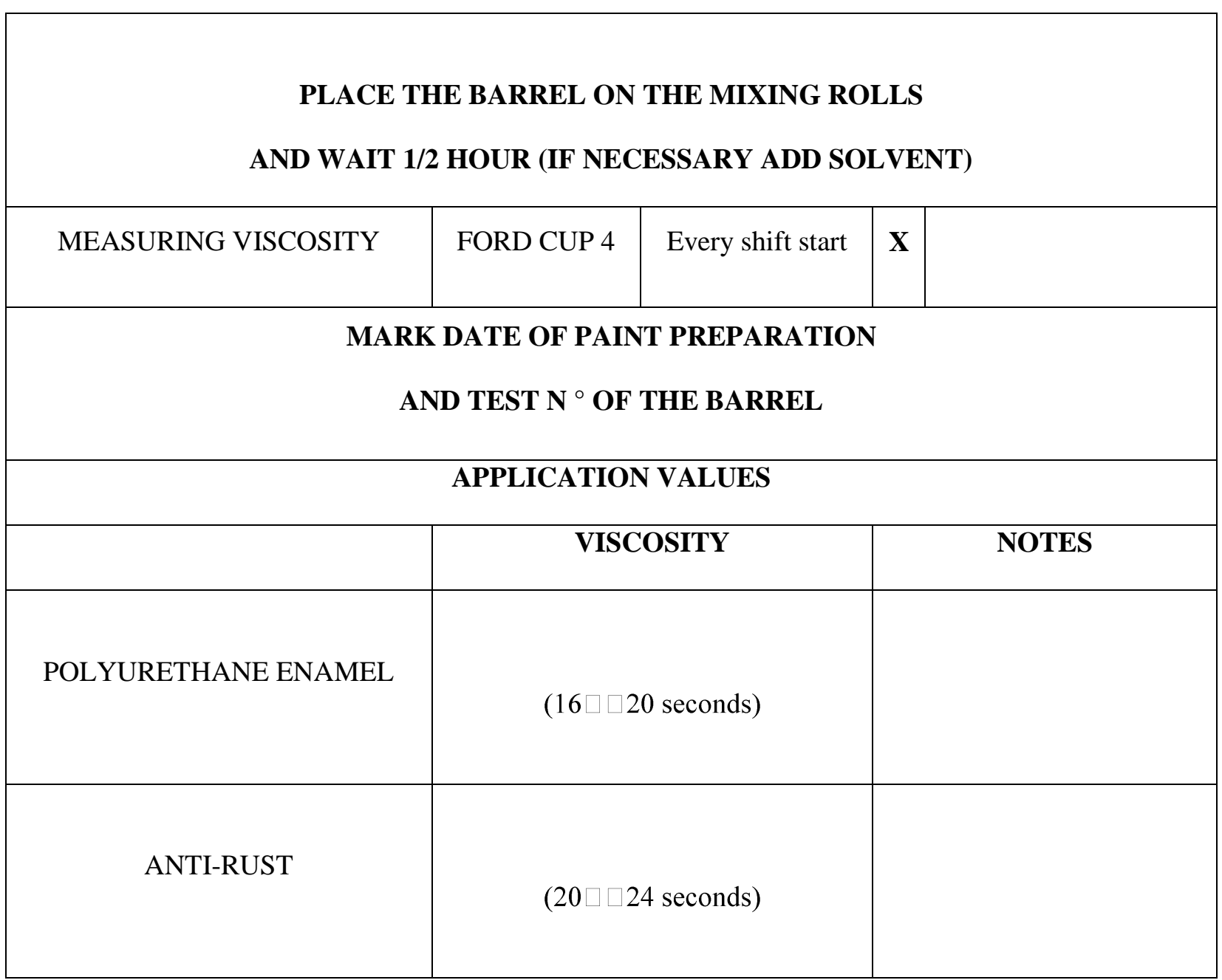

Figure 8

\begin{tabular}{|c|c|c|c|c|}
\hline & & \multicolumn{2}{|c|}{$\begin{array}{l}\text { SELF-CHECK CYCLE } \\
\text { PAINTING SYSTEM } \\
\text { JOLLY }\end{array}$} & $\begin{array}{l}\text { Issued on } \\
\text { Revision nr }\end{array}$ \\
\hline $\mathbf{N}^{\circ}$ & OPERATION & CONTROL & $\mathbf{R}$ & FREQUENCY \\
\hline 1 & GUN PRESSURE CHECK (enamel and anti-rust 2.5 bar) & MANOMETER & $\mathbf{x}$ & Every shift start \\
\hline 2 & CHECK THE OPERATION OF THE AGITATOR & VISUAL & $\mathbf{x}$ & Every shift start \\
\hline 3 & ANTI-RUST VISCOSITY GUN OUTLET (20 - 24 seconds) & FORD CUP 4 & $\mathbf{X}$ & Every shift start \\
\hline 4 & VISCOSITY ENAMEL GUN OUT (16 - 20 seconds) & FORD CUP 4 & $\mathbf{X}$ & Every shift start \\
\hline 5 & ANTI-RUST CATALYSIS REPORT $(100 \square 15)$ & $\begin{array}{l}\text { Volume ratio. } \\
\text { Check control unit setting }\end{array}$ & $\mathbf{x}$ & Every shift start \\
\hline 6 & ENAMEL CATALYSIS REPORT (1 $\square$ 2) & $\begin{array}{c}\text { Volume ratio. } \\
\text { Check control unit setting }\end{array}$ & $\mathbf{x}$ & Every shift start \\
\hline 7 & NOZZLE TYPE ANTI-RUST GUNS (Airles 215) & VISUAL & $\mathbf{x}$ & Every shift start \\
\hline
\end{tabular}


Mediterranean Journal of Basic and Applied Sciences (MJBAS)

Volume 4, Issue 4, Pages 136-166, October-December 2020

\begin{tabular}{|c|c|c|c|c|}
\hline 8 & FUNCTIONAL CHECK OF ANTI-RUST GUN NOZZLE & VISUAL & $\mathbf{X}$ & Every shift start \\
\hline 9 & NOZZLE TYPE ENAMEL GUNS (Airles 415) & VISUAL & $\mathbf{X}$ & Every shift start \\
\hline 10 & ENAMEL GUN NOZZLE FUNCTIONAL CHECK & VISUAL & $\mathbf{X}$ & Every shift start \\
\hline 11 & CHECK ANTI-RUST OVEN TEMPERATURE $(60 \square 65)^{\circ} \mathrm{C}$ & THERMOMETER & $\mathbf{X}$ & Every shift start \\
\hline 12 & ENAMEL OVEN TEMPERATURE CHECK $(80 \square 85)^{\circ} \mathrm{C}$ & THERMOMETER & $\mathbf{X}$ & Every shift start \\
\hline 13 & $\begin{array}{l}\text { MAINS AIR PRESSURE CHECK ( } 6 \text { bar) } \\
\text { PULVERIZATION AIR ( } 4.2 \text { bar) } \\
\text { FAN AIR ( } 0 \text { bar) }\end{array}$ & MANOMETER & $\mathbf{X}$ & Every shift start \\
\hline 14 & $\begin{array}{l}\text { CHECK INLET PRESSURE AT THE PROMIX OF THE PAINT } \\
\text { AND THE CATALYST }\end{array}$ & MANOMETER & $\mathbf{X}$ & Every shift start \\
\hline 15 & $\begin{array}{l}\text { CAREFUL WASHING OF THE CIRCUITS DOWNSTREAM OF } \\
\text { THE PROMIX }\end{array}$ & $\begin{array}{l}\text { WASH WITH PAINT } \\
\text { PASS ( } 3 \text { min approx.); } \\
\text { WASH } \\
\text { WITH SOLVENT }(5 \mathrm{~min})\end{array}$ & $\mathbf{X}$ & Every shift start \\
\hline 16 & $\begin{array}{l}\text { DISASSEMBLING THE GUN NOZZLES, PERFORMING A } \\
\text { THOROUGH CLEANING AND CHECKING THE CONDITION }\end{array}$ & $\begin{array}{l}\text { VISUAL OF THE } \\
\text { NOZZLE HOLE; } \\
\text { BLOWING WITH AIR; } \\
\text { IMMERSION IN } \\
\text { SOLVENT FOR } 15 \text { h; } \\
\text { VISUAL OF DAMAGES }\end{array}$ & $\mathbf{X}$ & Every shift start \\
\hline
\end{tabular}

Figure 9

\section{CHECK PIECES}

The check must be performed on all the details. The operator:

- proceeds with the prescribed checks following the painting self-check cycle;

- write the required measurements on the card;

- in the event of non-compliance, report the anomaly on the painting anomaly registration form;

- fill in the Declaration of Conformity, coming from the previous departments.

\section{Tools for defining criticalities and for problem solving}

To relate the problems to their causes, we used the ISHIKAWA or "FISHBONE" diagram (problem solving techniques). For the construction of the diagram we first identified the effect to be analyzed (dripping and missing parts of paint), the basic graphic scheme was set (the main $5 \mathrm{M}$ categories), we listed the main factors for each category and specified for each main factor all the factors that can be considered as causes, proceeding more and more in detail. Subsequently, from research carried out on the phenomenon of drippings, we focused attention on the causes closely related to the problem to try to guide the choice of solution strategies dividing them into the $5 \mathrm{M}$. As an example, the two M Machine and Man are shown:

\section{1) MACHINE}

- nozzles clogging;

- $\quad$ specific circuit clogging of the gun (circuit downstream of the promix) 
- promix input-output pressure

- automatic stop of the system.

2) $M A N$

- incorrect positioning of the pieces during the entrance phase in the cabin;

- manual painting of parts that cannot be painted automatically;

- maintenance operations at the beginning and end of the shift.

For each cause closely related to the problem of drippings, we have listed the description of the anomaly and the immediate corrective action.

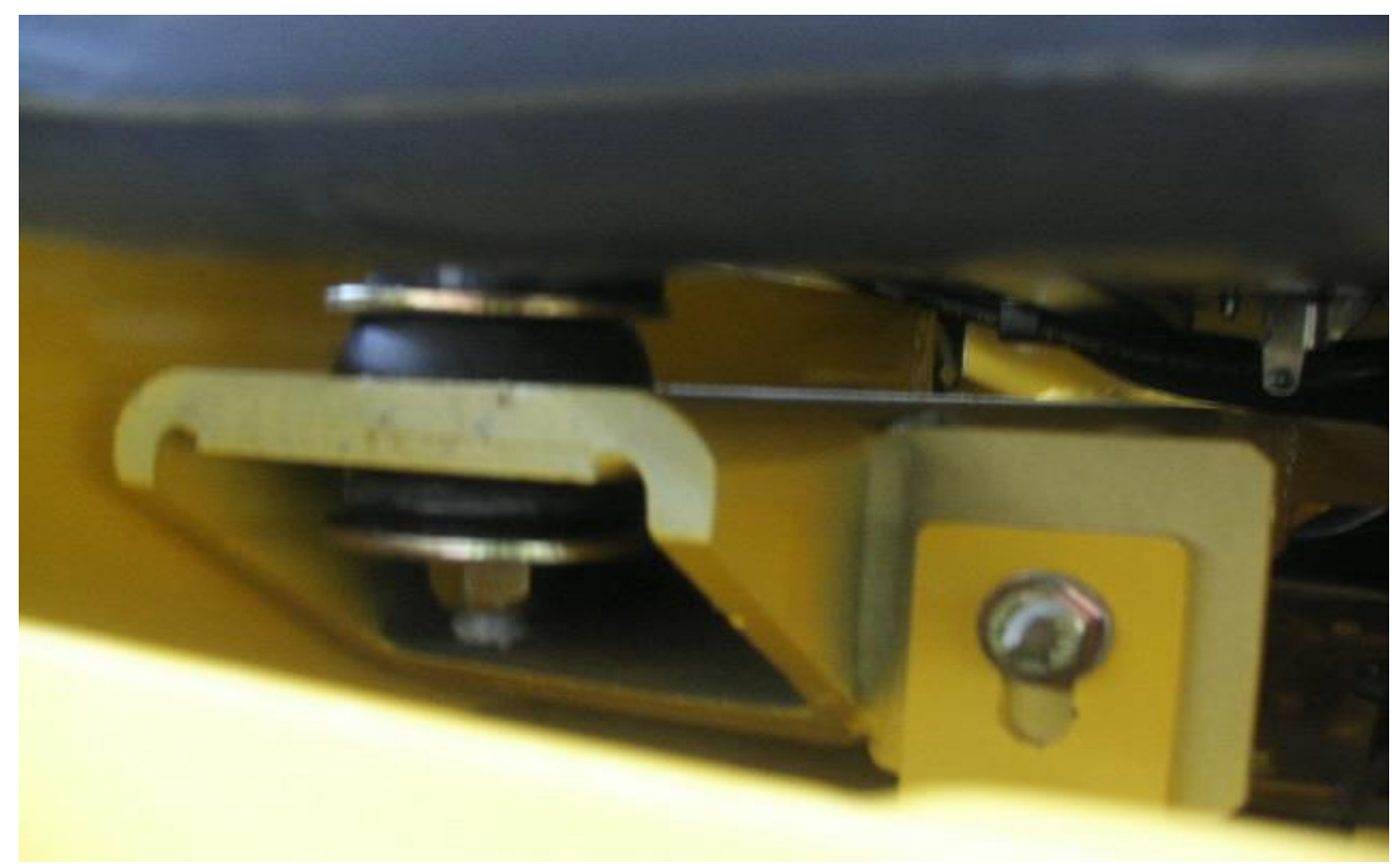

Fig.10. Partially painted front and internal supports for telehandler cab attachment

\section{1) MACHINE}

\section{-Nozzles}

Description of the problem: one of the main causes is represented by the clogging of the nozzles of the spray guns of the painting robots.

Corrective action: cleaning and restoring the nozzles.

\section{-Gun}

Description of the problem: The integrity and correct functioning of the gun is of fundamental importance. One of the main causes is represented by the specific circuit clogging of the gun (circuit downstream of the promixes) of the painting robots.

Corrective action: cleaning the gun and washing the circuits or replacing damaged components. 
-Promix

Description of the problem: The control of the promix inlet-outlet pressure is of fundamental importance

Immediate corrective action: the repair of this sub-group of the system.

-General stop of the plant

Description of the problem: of fundamental importance is the restoration and restart of the system following a temporary internal or external stop due to multiple causes (collisions, manual painting of the pieces, ...).

Immediate corrective action: the restoration of the system after the internal stop for painting pieces manually or externally and reporting the problem detected to maintenance department.

2) $M A N$

-Manual pre-painting operation

The pre-painting operation consists in applying the glaze to the parts not reachable by the painting robots.

Description of the problem: uneven application of the enamel layer can cause subsequent dripping or uncovered parts after the automated painting phase of the piece.

Immediate corrective action: the restoration of dripping or uncovered parts.

Scheduled maintenance and self-maintenance cycles

For all the causes found, we have linked the corrective actions with the tools suitable to avoid the critical issues and suggestions subsequently adopted for the modification of "dangerous" maintenance actions, the management of self-control in the painting department and for better organization and information of the work. Before making an outline of the various causes with their respective improvements, we have analyzed the activities already foreseen in the implementation of the maintenance plan (see table 2) relating to the robots of the automatic jolly painting plant and relating to all components.

Table 2: Jolly system maintenance

\begin{tabular}{|c|c|c|c|c|c|}
\hline & \multicolumn{5}{|c|}{ ROBOT 1 } \\
\hline \multirow{3}{*}{ NR } & GUN & GUN BASE & CHECK WITH & NOZZLE & NOZZLE \\
& REPLACEMENT & REPLACEMENT & TEMPLATE, & REPLACEMENT & HOLDER \\
& & & MORE AIR PIPES & & \\
& & & & & \\
& & & & & \\
\hline
\end{tabular}

For each component we have evaluated and implemented the preventive actions envisaged and presented our suggestions of both technical and managerial nature after having carried out the research on the operating methods of these maintenance activities: 
-Nozzles

Expected preventive actions:

1) At the end of the shift, remove the nozzles, perform a thorough cleaning and check their condition (any damage). Overnight they are left immersed in the solvent (internal maintenance department).

2) Check the functionality of the nozzles at the beginning of each shift (internal maintenance department).

3) Viscosity check at the beginning of each shift (external maintenance).

4) Every week check the cleanliness of the paint filters downstream of the pumps and cartridge filters of the tanks (internal maintenance).

In what follows, the operating methods of the operations are described in detail.

a) Nozzle disassembly:

1. removing the nozzle from the gun;

2. visual check of the clogging of the nozzle hole;

3. blowing with compressed air gun;

4. cleaning the nozzle with a blade;

5. visual check of any damage;

6. immersion in a solvent container for about 15 hours;

7. weekly replacement of the nozzle seal.

b) Nozzle functionality check:

1. mounting the nozzle;

2. visual nozzle functionality check: the robots operating mode is converted, passing from automatic to manual operation and visually checking the fan of paint coming out of the nozzle.

c) Viscosity control:

1. control of viscosity with ford 4 cup (the cup is filled and the glaze release time is measured);

2. control of the internal temperature of the system and reading of the data on the installed thermometer;

3. comparison of the measured values (viscosity and temperature) with a reference curve: if the data shows a deviation from the nominal viscosity value with respect to the measured temperature value of $+/-3$, the paint is mixed with the solvent operating iteratively until reaching a viscosity value that falls within the optimal range;

4. the viscosity value is checked iteratively, using the ford cup 4 (as an indication, $10 \%$ of solvent or paint is added to increase or decrease the viscosity value by approx. 2 units).

d) Cleaning filters: 
1. insulation and disassembly of the filters (by means of flow switches the circuits containing the filters are closed, the paint contained in the filter tank is discharged, the filter is disassembled);

2. washing with solvent (immersion for about 3-4 hours);

3. blowing of the filters with a compressed air gun;

4. further cleaning with brush and solvent;

5. the verification of the proper functioning of the filters is guaranteed by the control of the pressures by means of pressure gauges at the inlet and outlet of the circuits containing the filters;

6. this operation is identical for all types of filters;

7. replacement takes place if step 5 is not guaranteed.

\section{-Guns}

\section{Expected preventive actions:}

1. At the end of the shift, check the status of the guns and carry out a thorough cleaning; remember that the product is catalysed, failure to clean blocks their functionality (internal maintenance department)

2. At the end of the shift, wash the circuits downstream of the promixes. (internal maintenance department)

3. At the end of the shift, if necessary, repeat or extend the washing times. (internal maintenance department)

4. When starting up the system, check on the electro-pneumatic panels: the network air pressure (6 bar); the atomization air pressure ( 4.2 bar $)$; the fan air pressure $(0$ bar $)$ (internal maintenance department)

Below are the operating methods of the operations described above.

a) Gun cleaning:

1. removing the nozzle from the gun;

2. visual check of the clogging of all the gun holes;

3. blowing with compressed air gun;

4. cleaning the gun with solvent and brush;

5. visual check of any damage;

6. check for any clearances in the gun.

b) Washing the circuits downstream of the promix:

1. through the instrument panel, the paint present in the circuit downstream of the promix is discharged (duration 3 $\min )$;

2. switch to manual mode of the system; 
3. washing of the circuit downstream of the promixes with solvent for approx. 5 min.

c) Washing:

1. repeat operation b) several times, selecting washing from the instrument panel to ensure thorough cleaning of the system.

d) Check of the system parameters:

1. visual check of the relevant plant parameters:

- network air pressure (6 bar);

- atomization air pressure (4.2bar);

- fan air pressure (0 bar).

- Promix

Expected preventive actions:

1. at the beginning of the shift, check the inlet pressures of the paint and catalyst promixes (4 bar) (internal maintenance department)

2. Check the product / catalyst ratio on promixes 1 and 2 every week.

Below are the operating methods of the activities described above:

a) Pressure check: visual check of the pressures on the promix pressure gauges.

b) Check the catalyzation ratio: check from the system instrument panel.

-Stopping the system

Expected preventive actions:

1. control process during the entry of the pieces into the cabin (painting department operators)

2. restoration of the system after the internal stop for painting pieces manually or externally and reporting the problem detected to maintenance (painting department operators).

Below are the operating methods of the activities indicated above.

a) Restoring system:

1. check the system shutdown time on the promix instrument panel;

2. assess if restoration is possible or if maintenance must be requested;

3. wash the circuits downstream of the promix (with paint) if the stopping time does not exceed $30 \mathrm{~min}$.;

4. wash (with solvent) and then reload the paint if the stopping time exceeds 60 minutes;

5.Visual check of the restoration and the spray pattern. 
Based on the results that emerged, we have implemented the self-control system with the inclusion of maintenance activities and its own methods from the analysis described above. For the problems and criticalities of manual painting of agricultural and earthmoving machinery components, we suggested:

1) to adopt the display of visual control cards for the parts to be painted manually (painting department operators);

2) to use of cards with graphic of the group to be painted to indicate the areas to be repaired due to drippings or uncovered parts (painting department operators).

The first type of cards (fig. 11 and 12) is used by the operator to focus on the critical points for the complicated geometry of the piece and therefore to pay more attention in those areas.

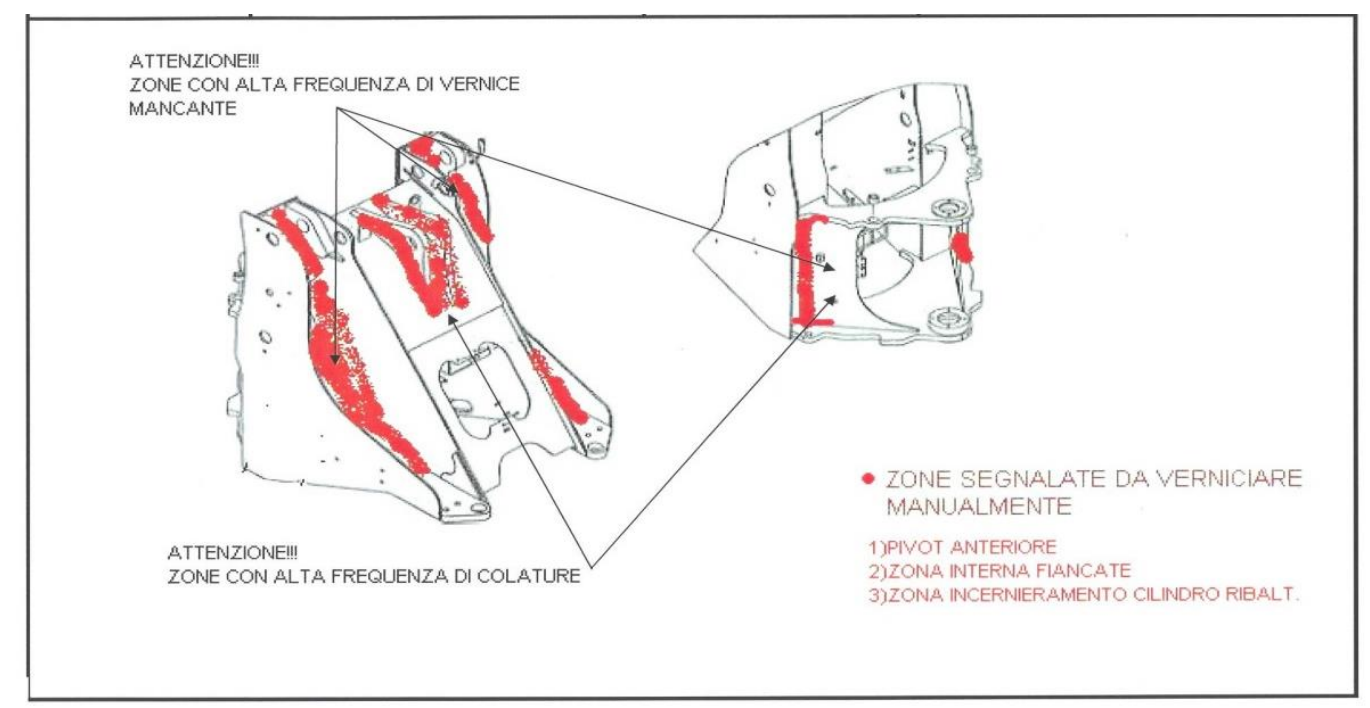

Fig.11. Front Frame

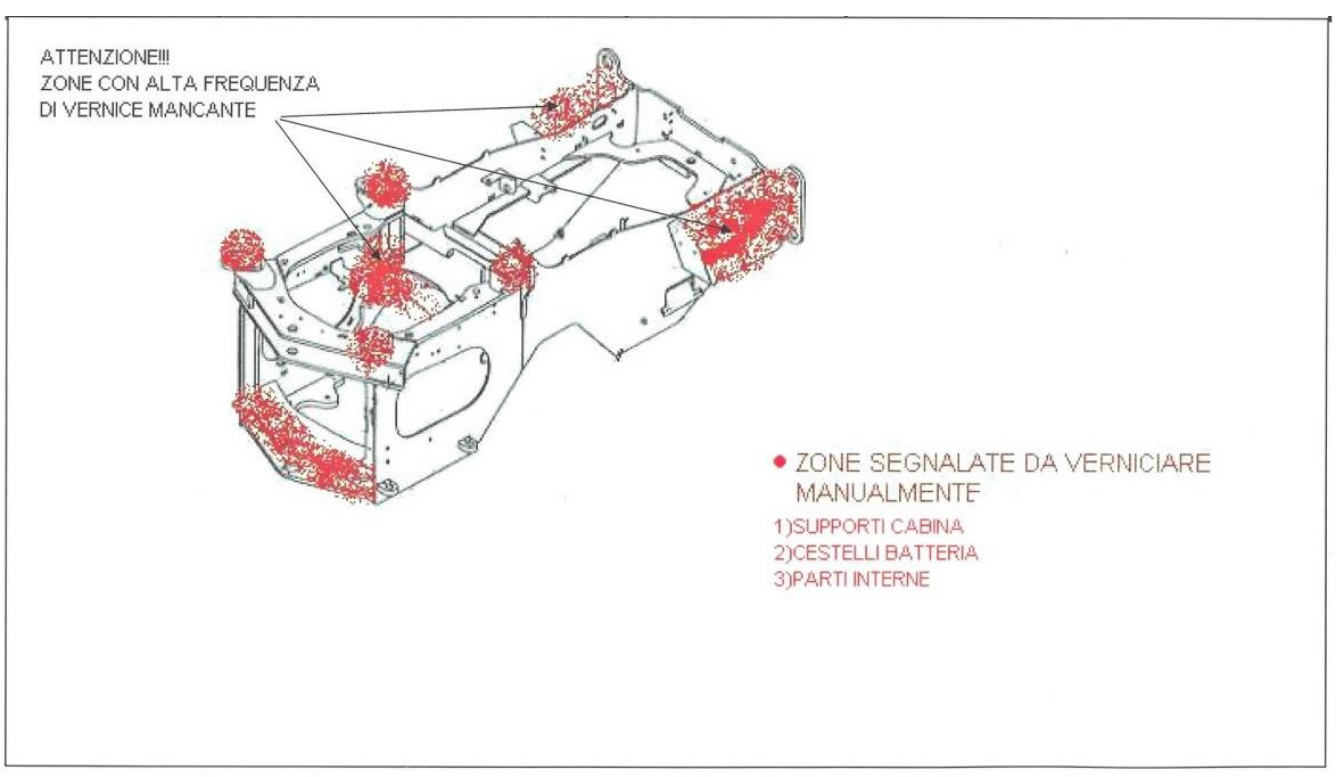

Fig.12. Rear Frame

The second type of cards (fig. 13 and 14) is used to record the anomaly of the defective piece and to report the area and the type of anomaly to the bodies in charge. 

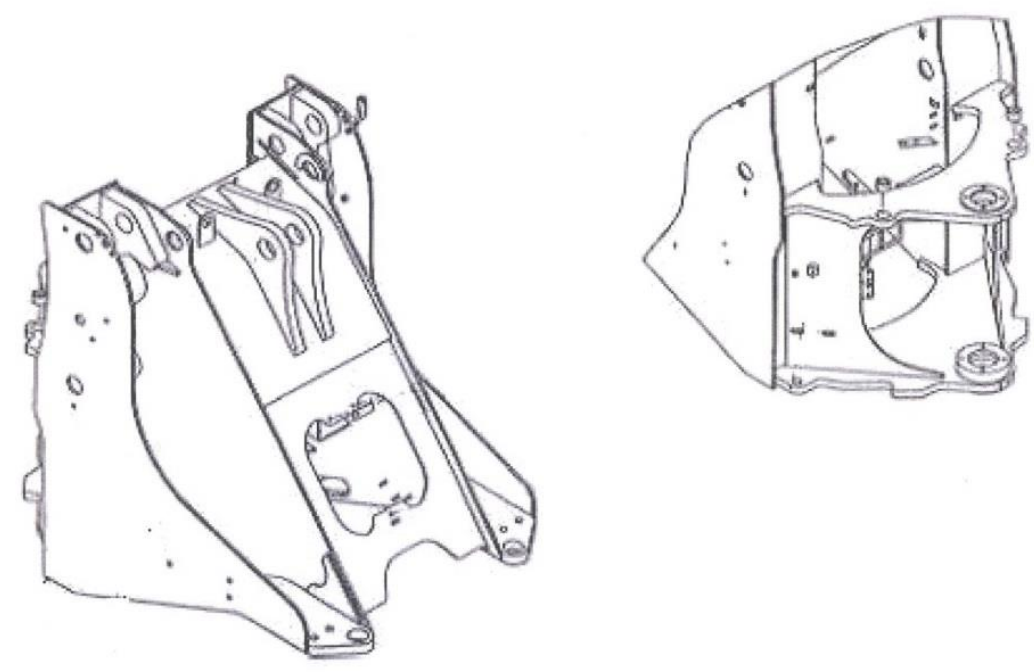

Fig.13. Front Frame

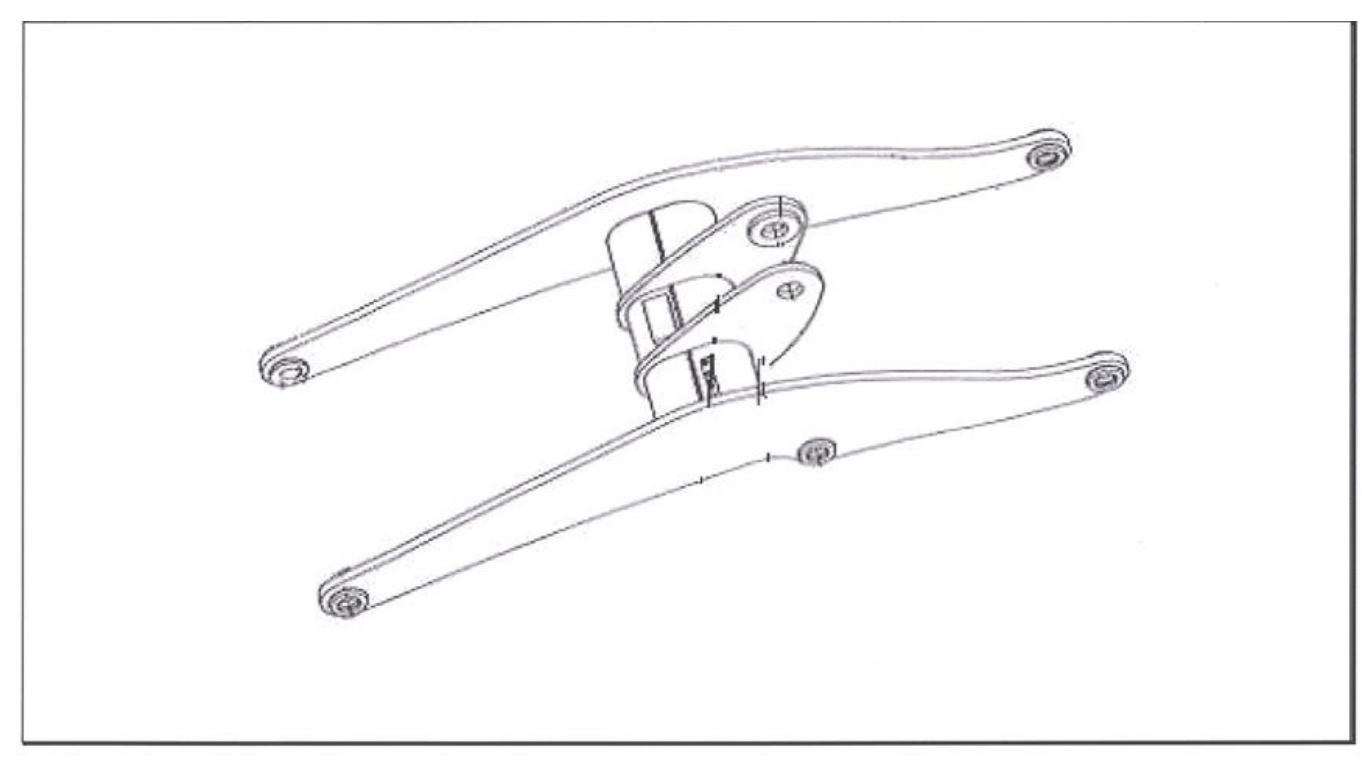

Fig.14. Arm

\section{Results and Discussion}

To analyze the situation, we collected and numerically ordered the data (table 3 and 4) with a new monitoring of the defective parts and we highlight the differences that are already evident with the new working approach.

Table 3: Final defective parts detection

\begin{tabular}{|c|ccc|}
\hline $\begin{array}{c}\text { PARTS DETECTED } \\
\text { DEFECTIVE }\end{array}$ & DAY & $\begin{array}{c}\text { DRIPPINGS } \\
\text { (COLATURE) }\end{array}$ & $\begin{array}{c}\text { DISCOVERED } \\
\text { PARTS (PARTI } \\
\text { SCOPERTE) }\end{array}$ \\
2 & 1 & 2 & 1 \\
1 & 2 & 1 & 0 \\
1 & 3 & 1 & 0 \\
\hline
\end{tabular}




\begin{tabular}{|c|c|c|c|c|}
\hline & 1 & 4 & 1 & 2 \\
\hline & 1 & 5 & 2 & 1 \\
\hline & 1 & 6 & 0 & 1 \\
\hline & 1 & 7 & 1 & 0 \\
\hline & 1 & 8 & 1 & 0 \\
\hline & 2 & 9 & 2 & 1 \\
\hline tot. & 11 & & 11 & 6 \\
\hline
\end{tabular}

Table 4: Initial defective parts detection

\begin{tabular}{|c|ccc|}
\hline $\begin{array}{c}\text { PARTS DETECTED } \\
\text { DEFECTIVE }\end{array}$ & DAY & $\begin{array}{c}\text { DRIPPINGS } \\
\text { (COLATURE) }\end{array}$ & $\begin{array}{c}\text { DISCOVERED } \\
\text { PARTS (PARTI } \\
\text { SCOPERTE) }\end{array}$ \\
\hline 1 & $23 / 05 / 2005$ & 3 & 0 \\
\hline 3 & $24 / 05 / 2005$ & 3 & 1 \\
\hline 1 & $27 / 05 / 2005$ & 1 & 1 \\
\hline 1 & $01 / 06 / 2005$ & 2 & 2 \\
\hline 2 & $03 / 06 / 2005$ & 2 & 4 \\
\hline 4 & $06 / 06 / 2005$ & 6 & 1 \\
\hline 1 & $12 / 06 / 2005$ & 3 & 0 \\
\hline 14 & $17 / 06 / 2005$ & 1 & 11 \\
\hline
\end{tabular}

For a duration of monitoring of about 20 days there was a decrease in the detected defective pieces, (from 14 pieces to 11 pieces), but even more significant is the decrease in the total number of defects on the pieces (from 32 detected defects to 17). So on a scheduled daily production of approx. 30 pieces, the defect was $2.3 \%$ while at final it has dropped to $1.8 \%$. In addition to these tangible results, which are very important, the greatest competitive advantage achieved by the companies that have applied the TPM consists in the high ability to continuously improve processes to meet the ever-increasing market needs.

We also tried to develop an organic method for the implementation of such a significant change process for the analyzed painting department through gradual, monitored steps and to develop a set of clear and efficient tools for managing the various activities. Our work of analyzing all the criticalities of the painting plant and related maintenance activities has resulted in the use of the self-control system to get feedback on the activities carried out and in the use of reference information tools to improve, report and eliminate defects on the pieces. We have also 
modified a planned maintenance activity of the nozzles: the replacement of the nozzle holder gasket, because during the disassembly and reassembly of the nozzle the gasket was damaged by altering the paint pattern.

\section{Conclusions}

From the study carried out, the advantages linked to the transition from a maintenance system managed mainly by failure to one based on TPM that is on planning, on the timely recording of the activities carried out and on the management of maintenance activities, are evident. Such a process presents considerable difficulties related to personnel and methods of changing mentality. Surely it is necessary to incur additional costs, but the advantages that can be obtained are considerable above all for the improvement of the productivity and efficiency of the plants. Increasing flexibility and involving staff towards continuous improvement are fundamental steps to determine the success of a company. The application of the TPM in the painting department and, in particular, the implementation of the self-control management system represent a crucial factor for the improvement and the growth of the organization in the current business context in which factories with high automation link their production output, in quantitative and qualitative terms, to the correct functioning of the machinery. These high goals are achievable only by great perseverance because they require the involvement of the entire company structure.

\section{Bibliography}

[1] Farné S., Application and Results of the TPM Methodology in a Factory for the Production of Agricultural and Earth-Moving Machines, Asian Journal of Basic Science \& Research Volume 2, Issue 4, Pages 01-11, October-December 2020

[2] Fitch E. C., Proactive Maintenance for Mechanical Systems, 1992 Elsevier Advanced Technology

[3] Anderson, R.T., Neri, L., Reliability-Centered Maintenance: Management and Engineering Methods, 1990, Springer Netherlands

[4] Moubray J., Reliability-Centered Maintenance, 1997, BH.

[5] Fumio Gotoh, Equipment Planning for TPM (Total Productive Maintenance Series), 1991, Prod. Press Inc.

[7] Fedele L., Furlanetto L., Saccardi D., Progettare e gestire la manutenzione, Mcgraw-Hill, Milano, 2004.

[8] JIPM, Applichiamo il TPM: guida operativa alla realizzazione del Total Productive Maintenance, Franco-Angeli, Milano, 2000.

[9] Nakajima S., TPM: Total Productive Maintenance, Isedi, Torino, 1992.

[10] Mangiarino C., Gobetto M., Gestione sistemi tecnici di fabbrica, Politecnico di Torino, 2005.

[11] Roos D., Womack J.P., Jones D.T., La macchina che ha cambiato il mondo, Rizzoli, Milano, 1991.

[12] Crosby P., Quality is Free, Mcgraw-Hill, New York, 1979.

[13] TPM Development Program, Productivity Press, Cambridge. 
[14] Cozzari G., materiale didattico del corso di Tecnologia di assemblaggio, Politecnico di Torino, 2004.

[15] Farné S., materiale didattico del corso di Qualità e Misure, Politecnico di Torino, 2004.

[16] Pomorski T. R., Total Productive Maintenance Concepts and Literature Review, 2004

\section{Websites}

www.aiman.com | www.casere.com | www.abb.com | www.basf.com | www.jipm.com 